PROJECT No. DE - FC07 - 00ID13996

\title{
ROTARY BURNER DEMONSTRATION
}

FINAL REPORT; SEPTEMBER 2000 DECEMBER 2002

April 30, 2003

Prepared by:

Paul Flanagan,

Calcpos Engineering

PO Box 906,

Northfield Center, OH 44067

calcpos.pf@att.net

For:

U.S. Department of Energy, Idaho Operations Office, 850 Energy Drive, MS 1221, Idaho Falls, ID 83401 - 1563

Attn: John Yankeelov; Project Manager

\section{Distrubution by E Mail:}

yankeeja@id.doe.gov

kellerig@inel.gov

james.quinn@hq.doe.gov

psdrept@id.doe.gov

vanlencl@id..doe.gov

\section{NOTICE}

Re-organization of the US Department of Energy, Idaho eliminating petroleum projects resulted in the cancellation of existing projects in this energy sector. Accordingly this report can only present a final status report absent actual field test results on a complete heater installation. 


\section{0: GOALS}

Demonstrate a practical burner exhibiting the following characteristics:

[a] A compact flame envelope together with energy savings of $3.5 \%$ absent air blower support.

[b] Concurrent and ultra-low emissions of carbon monoxide [CO] and oxides of nitrogen [ $\left.\mathrm{NO}_{x}\right]$ in parts per million by volume [ppmv] as follows:

$$
\mathrm{CO}: \leq 30 ; \quad \mathrm{NO}_{\mathrm{X}}: \leq 10\left[\mathrm{NO}+\mathrm{NO}_{2}\right]
$$

[c] Ease of retrofit to an existing operational production heater.

[d] Safe, rugged, and reliable operation.

[e] Verify the above features after 8700 hours of production operations.

\section{0: BACKGROUND}

Texas A \& M University for Business Extension group performed a market study [2002] for DOE in order to confirm the Calcpos projections of the market potential.

\section{Value of Shipments for Top Refining States - 1996}

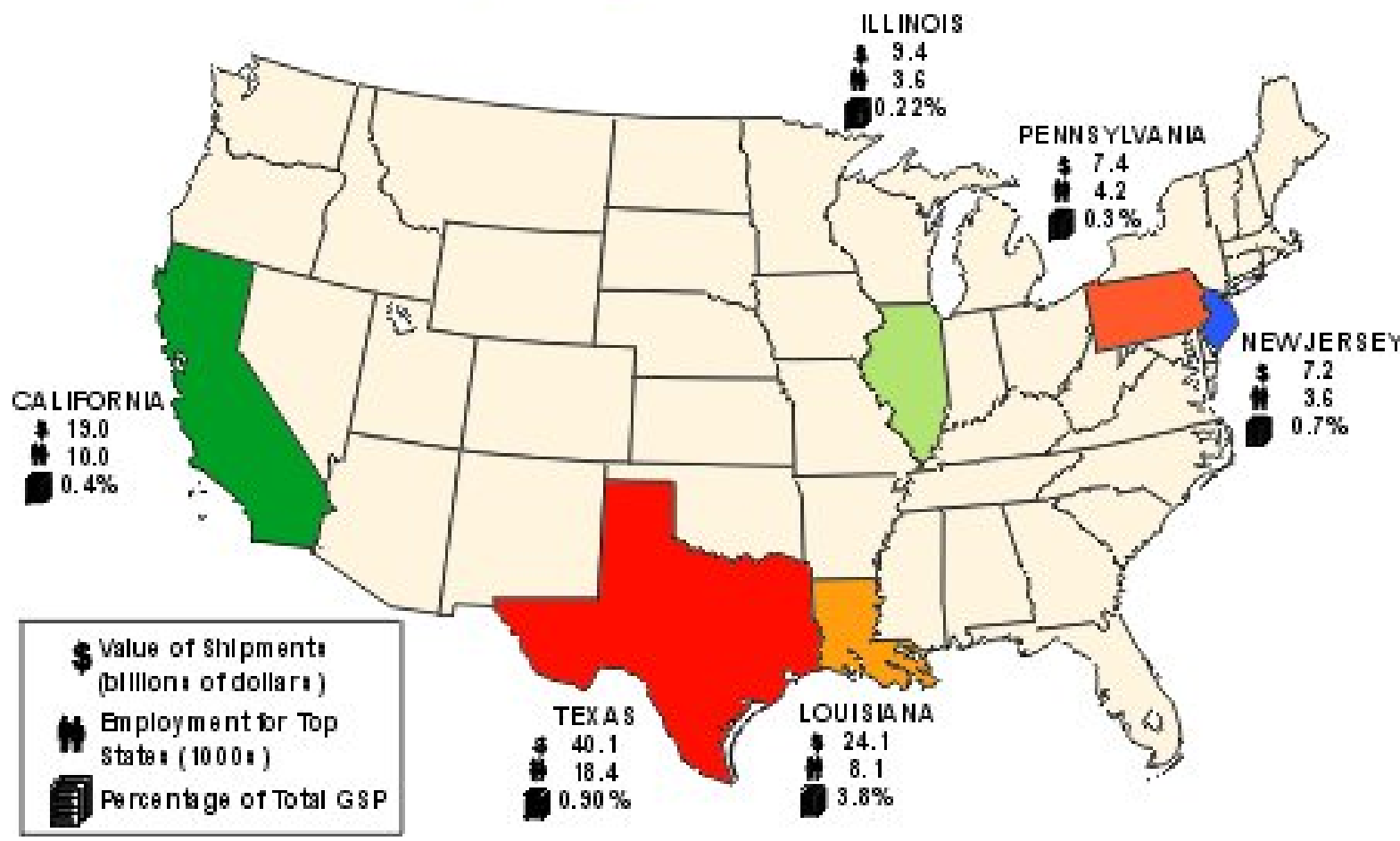

FIG 1 


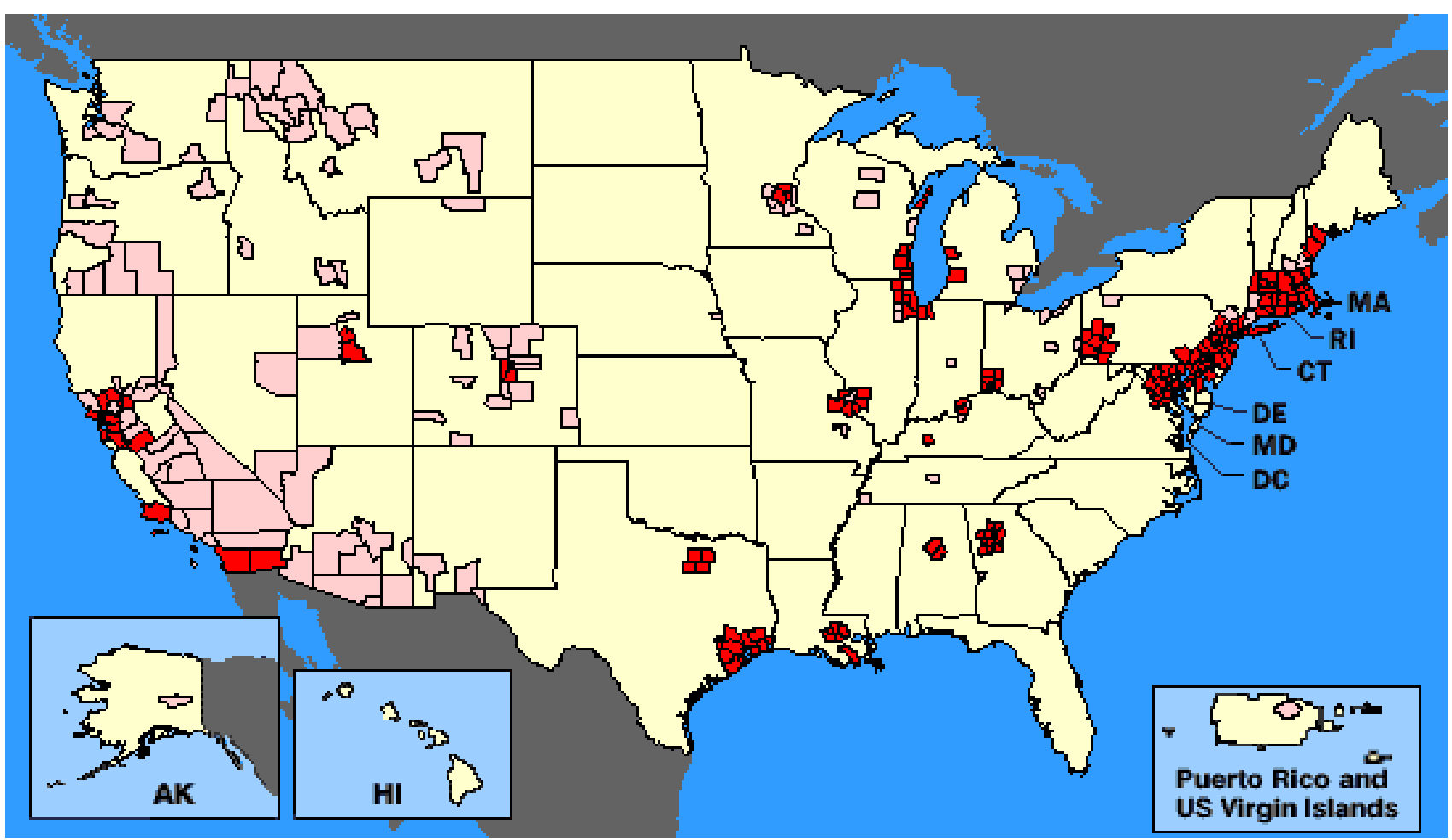

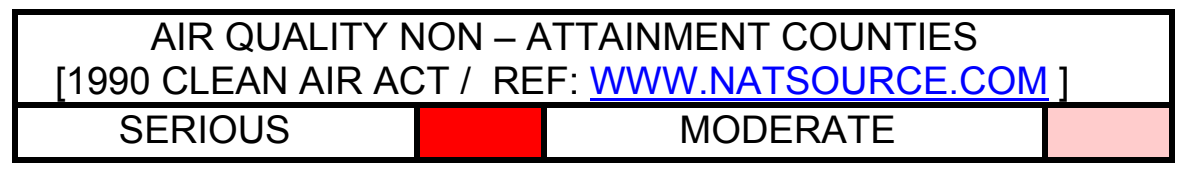

\section{Introduction}

FIG 2

The subject technology, the Calcpos Rotary Burner [CRB], is a burner that is proposed to reduce energy consumption and emission levels in comparison to currently available technology. Burners are used throughout industry to produce the heat that is required during the refining process. Refineries seek to minimize the use of energy in refining while still meeting EPA regulations for emissions.

\section{Technology Overview}

According to the inventor, the Rotary Burner technology provides energy savings derived through more efficient heat transfer and the elimination of electricity that is traditionally needed to operate a blower. In addition, the Rotary Burner offers ultra-low emissions. In a certified test, $\mathrm{CO}$ emissions were found to be near zero and $\mathrm{NO}_{x}$ emissions were less than 3 parts per million (ppmv). The subject technology also eliminates flame impingement which increases tube life and reduces fouling problems.

\section{Market Environment}

The city of Houston, Texas and the eight surrounding counties, are under regulation from the Environmental Protection Agency (EPA) and the Texas Natural Resource Conservation Commission to use only burners that release less than $10 \mathrm{ppm} \mathrm{NO}_{\mathrm{x}}$. 
Designated by the EPA as a 'non-attainment' zone, these regions must limit and reduce emissions through strict regulation and enforcement. Other regions of the United States have been classified as 'non-attainment' zones must lower emissions and are mandated to use low emission technology. In some cases refineries in these zones must implement Best Available Controls Technology. Thus, these non-attainment regions should be ideal targets for the rotary burner. The market demand for the low emission burners in the Houston area alone is over 400,000 MMBTUH.

When purchasing new burners refiners look for burners with the lowest energy consumption that is able to meet the emission requirements for the region. Refinery expenditures on pollution abatement equipment have risen from 10 percent to over 40 percent of total capital expenditures since the introduction of the Clean Air Act of 1990. Due to the location of many refineries within non-attainment areas, and the increased push for reduction in emissions in these areas, refiners will be subject to pressure to utilize low $\mathrm{NO}_{x}$ refinery equipment. No other available technology releases as little emissions as the subject technology claims. Several experts agreed that if the rotary burner performs as stated the technology would be well accepted in the petroleum, natural gas, and chemical refining industries. Reducing $\mathrm{NO}_{\mathrm{x}}$ emissions is a top priority of almost all refiners contacted. At least, five industry experts expressed interest in learning more about the subject technology and pursuing the possibility of a test installation.

Most industry experts recommended that the inventor partner with a refiner to implement a test installation. After the text installation the results should be shared with others in the industry.

\section{Barriers}

- Need for Test Installation ... Refiners would like to see the technology in operation before purchasing it. Members of industry are impressed with energy usage and emission results for the subject technology, but want to see it operate.

- Moving Parts ... Some industry experts are wary of a burner with moving parts. Moving parts have been a failure point for burners in the past. Calcpos must address this concern.

\section{Opportunities}

- Low Emission Burner ... Many refineries are located in areas where the use of low emission burners in mandated. The subject technology might be their only choice. Several experts stated this is the primary sales feature of the subject technology.

- Limited Competing Technology ... No real competition exists. Callidus produces a low $\mathrm{NO}_{\mathrm{x}}$ burner, but it still has an emission level three times that of the subject technology.

- Quick Payback Period ... The payback period for this technology is estimated to be six months. This is within the requirements of potential customers.

- Low Maintenance and Energy Costs ... These costs are lower than those of other burners on the market. 


\section{REPORT CONCLUSIONS}

There is a significant market looking for low emission burner technologies, and there is no other technology that fits this niche. The demand for this technology will increase, as more regions in the Unites States are classified non-attainment by the EPA. If the subject technology has a successful test installation and the inventor's claims are validated, the potential exists for successful market entry and product commercialization. Due to the concentration of energy industry sector operations in the Louisiana / Texas region this area was selected by Calcpos as the primary target location for the Phase II demonstration. Texas is also currently subject to more stringent emissions mandates further emphasizing the regional selection.

It is noteworthy that since FIG 2 was published that non-attainment status has been continuously expanded to increase beyond those shown. Currently a shortage of refining capacity exists; most operators being at essentially full capacity [ $90 \%$ ]; the majority of users are interested in increasing the output of existing equipment to provide an operational margin. This critical consideration renders most users very cautious about operational evaluations of new technology. The recurring problem of flame impingement upon the heater tubes, now further aggravated by low emission burners, was cited as the capacity limiting factor. By virtue of its ability to simultaneously provide ultra- low emissions and compact flame the CRB satisfies the newer more stringent burner performance demands. These factors were influential in obtaining the access to an operational site heater in SW Louisiana for field test and demonstration purposes.

\subsection{PHASE I: EQUIPMENT DESIGN \& LABORATORY TEST}

Clearly beyond all the above noted market and regulatory considerations successful product entry is dependant upon end-user satisfaction. These remain basically as defined in the project goals with hardware geometry modifications resulting from discussions with operators.

Design and Modifications: As planned attention was focused upon providing reliable equipment for the field test. Particular attention has been paid to the durability of sensitive components [ e.g. labyrinth seals] to ensure trouble-free operation and ease of

maintenance. Manufacturing methods and materials were addressed to ensure a satisfactory equipment payback.

Testing: A test rig shown in FIG 3 was erected for burner evaluation and pre-site demonstration and inspection purposes. 

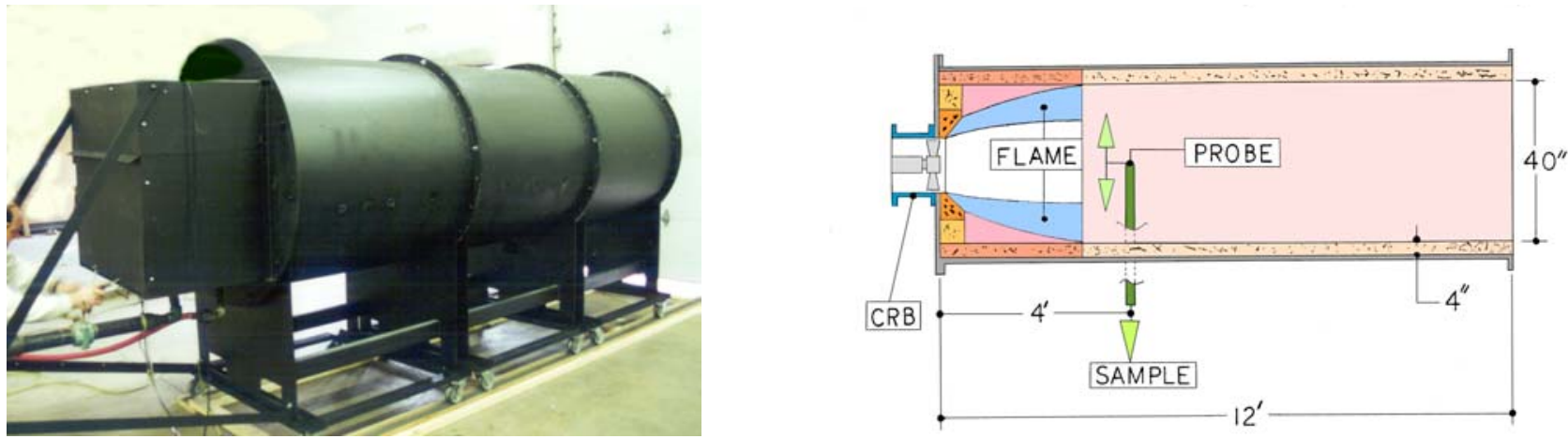

FIG 3

Functionally the rig was arranged to provide the most severe burner operating condition of horizontal firing i.e. absent the natural draft stack effect of the now more common vertical firing heaters. Since the refractory lined chamber operating temperature is typically above $2500 \mathrm{~F}$ it also presents a more difficult environment for control of $\mathrm{NO}_{\mathrm{x}}$ emissions than an operational heater.

Performance: CRB operational characteristics were evaluated both in the test heater and externally for chamber wall effect conditions, if any, upon the flame geometry. Flame photographs at the design rate of 10 MMBTUH are shown in Figure 4.

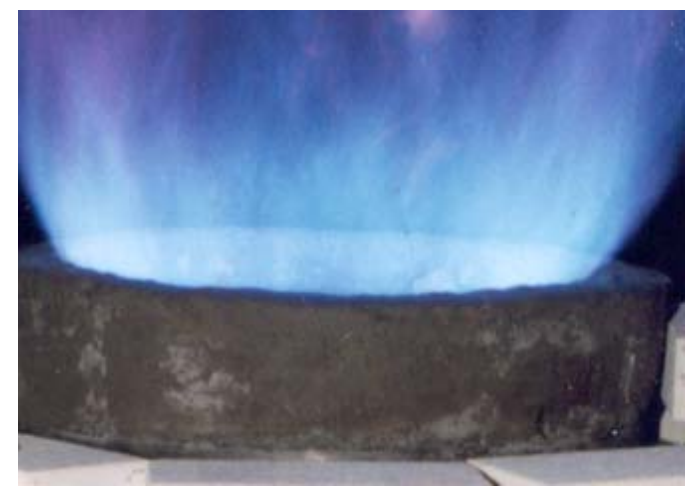

[a] EXTERNAL; AMBIENT

Block Dimensions

O. Dia. : 21 ins

I. Dia. : 14 ins

Height $: 7$ ins

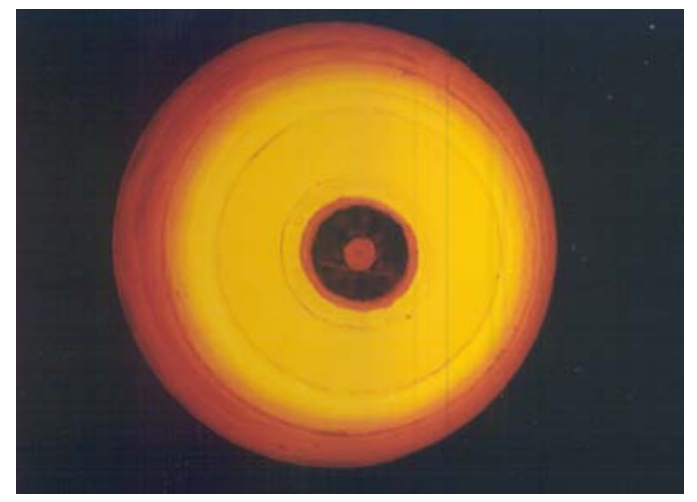

[b] INTERNAL; CHAMBER Chamber Dimensions

$\begin{array}{ll}\text { I Dia. } & : 40 \text { ins } \\ \text { Length } & : 48 \text { ins }\end{array}$

FIG 4

In both cases a compact non-impinging flame typically below 30 ins in length was observed. The cool central core is also clearly apparent. From FIG 4[b] the rapid heat release is seen in FIG 4[b] serves to provide much improved heat transfer rates and energy savings in heater operations. 
Emissions were measured using a water-cooled sample probe to freeze the sample at the selected axial location thus ensuring a true residence time for $\mathrm{CO}$ emissions. The results of earlier were confirmed as follows:

Design Point:

Turndown; $25 / 1$
$\mathrm{NO}_{\mathrm{x}} \angle 3$ ppmv;

$\mathrm{NO}_{\mathrm{x}} \angle 5 \mathrm{ppmv}$
$\mathrm{CO} \angle 10 \mathrm{ppmv}$

$\mathrm{CO} \cong 200 \sim 400 \mathrm{ppmv}$

At the extended of $25 / 1$ the increased $\mathrm{CO}$ emissions occur due to less vigorous mixing. Since only a 5 / 1 turndown is required in operation the field design is to be modified.

For ease of fabrication and cost control purposes mechanical modifications were also planned for the field test units.

Pilot ignition and main flame stability were excellent indicating the ability within current controls and eliminate the common pilot failure problem. No mechanical overheating occurred and material of construction problems were observed.

\section{Phase I: Project Expenditures}

DOE costs and commitments through October 1, 2001 as shown in FIG 5 represent $100 \%$ of the allocated funds.

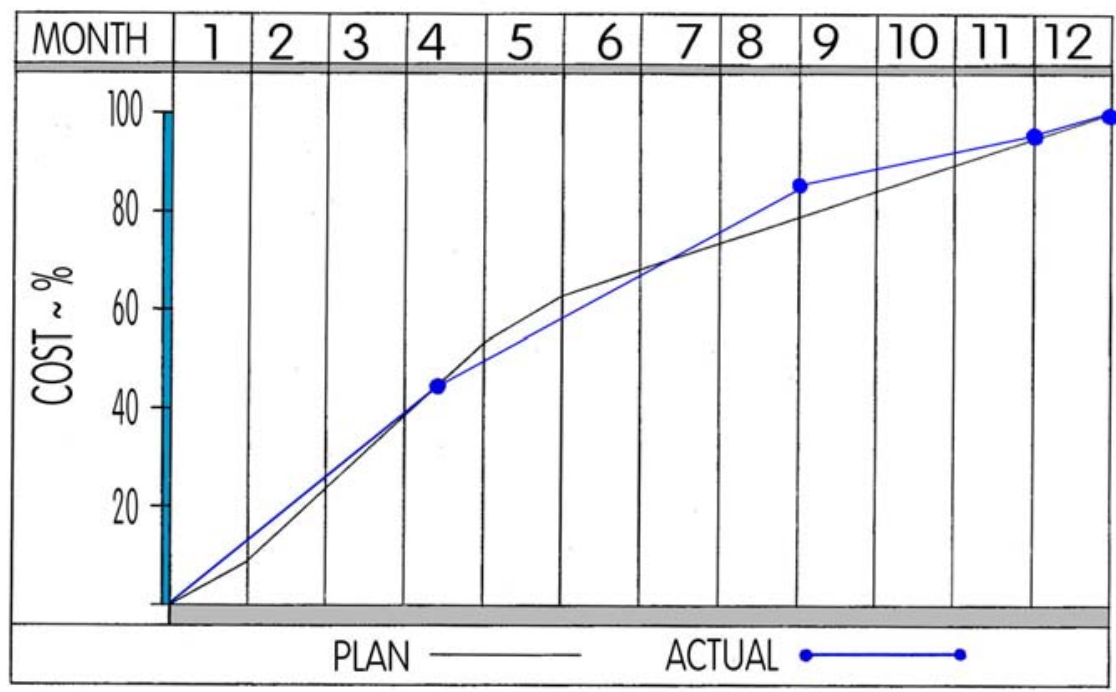

FIG 5: PH; I COSTS

The total Phase I cost of $\$ 246,000.00$ was funded as follows;

[a] US Department of Energy;

[b] Calcpos Engineering;

NOTE: Cost sharing [b] does not include $\$ 19,000.00$ cost for the unplanned Task 18; Design and Fabrication of Laboratory Test Rig. These funds were provided by Calcpos. 


\section{0: PHASE II: FIELD TEST}

Work performed through December 31, 2003 continued ahead of the planned schedule as shown in the attachment [DOE F4600.3; Appendix A]. The principal comments are:

Burner \# 1 [ commissioned on June 15, 2002 ] is shown in FIG $\mathbf{5}$ is operating continuously absent maintenance or special attention; this is very noteworthy for the initial field use of a new equipment design.

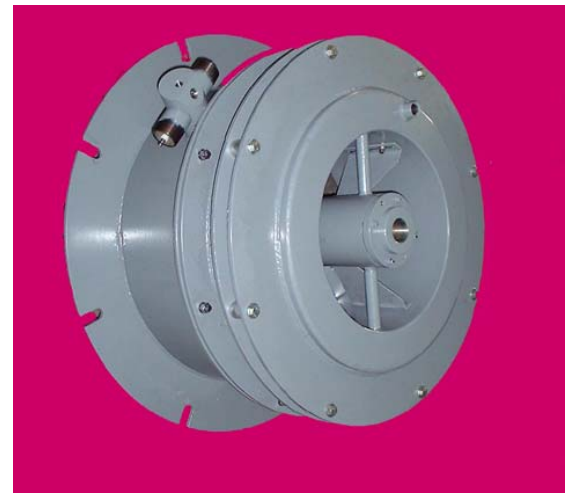

INLET VIEW

\section{FIG 5}

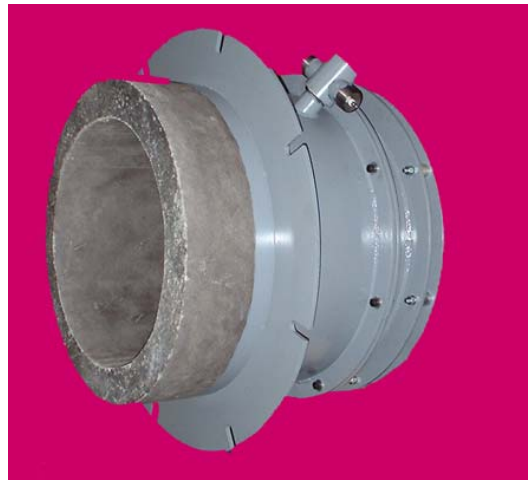

[b] FRONT \& SIDE VIEW

Burners \# 2 \& 3 shown in FIG 6 incorporating site recommended modifications were installed on site in October 2002. These burners were installed at-risk to the Calcpos account pending DOE continued funding beyond September 2002; as noted this did not occur.

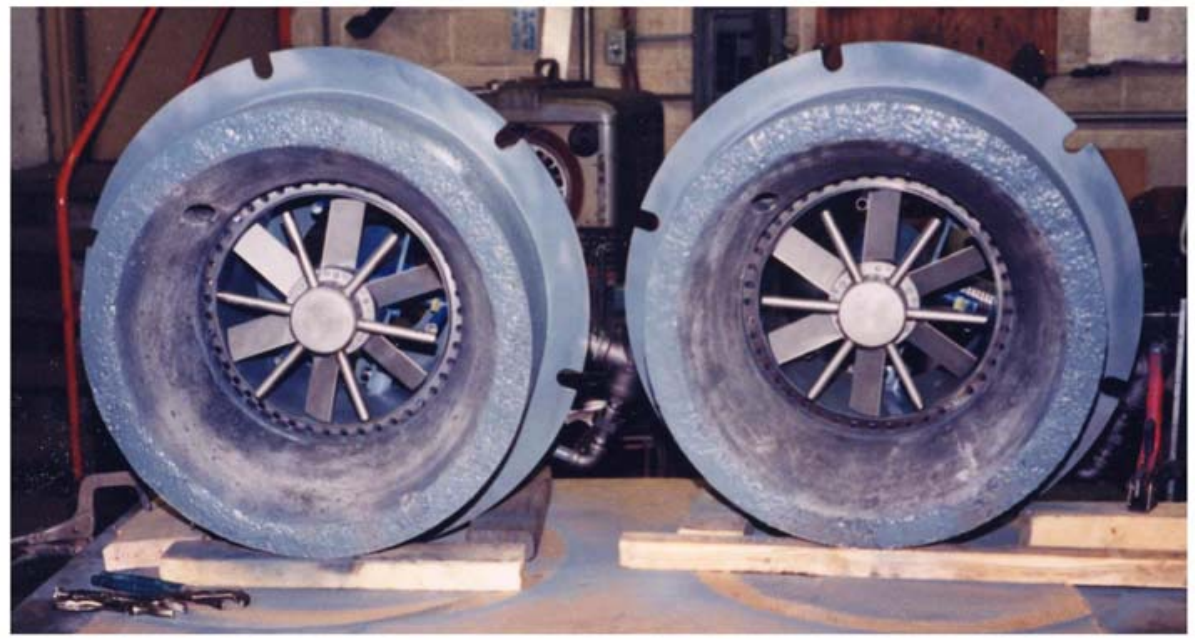

FIG 6: BURNERS 2 \& 3

These burners continue to run successfully as of this date. Final adjustments and fuel main and trim control settings were not performed 
The heater represents a most rigorous test case for the new CRB technology; existing deficiencies relating to its exhaust capability, internal combustion gas flow patterns, and pressure distribution being observed. Visual observations of the CRB demonstrated ability to provide the characteristic compact hard flame [as compared to the more erratic behavior of the existing burners] under these operational conditions.

The partial DOE project funding through September 9, 2002 was exhausted; thus as advised the work reported herein was performed pending final resolution of federal re-organization.tion. As shown FIG 7 the project costs to date remain in accordance with the planned projection and timing. Work on the maintenance and operational manual has commenced. This requirement was to be completed upon completion of the remaining burner installations to determine the optimum set-up procedures. The expenditures through December 31, 2002 are shown in FIG 7.

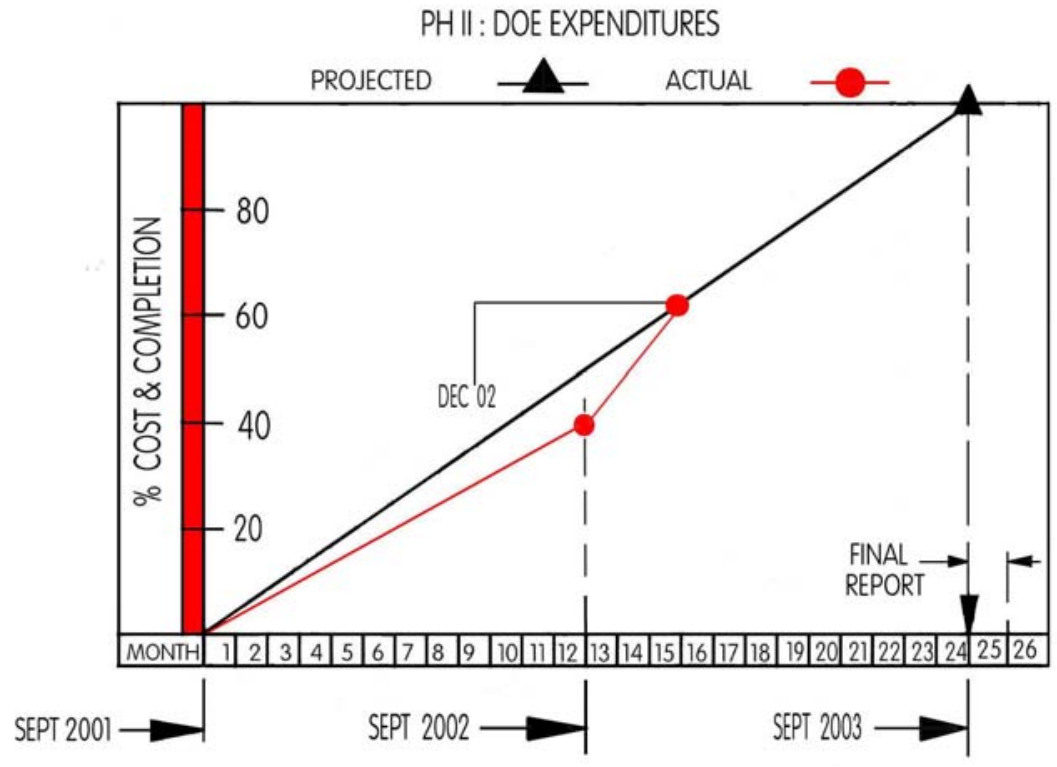

FIG7: PH II; COSTS 
APPENDIX A: REPORT APRIL 30, 2003

Ref: DOE F 4600.3 Revised OMB Control No1910-0400

[ Page 1 of 2 ]

\section{U.S. DEPARTMENT OF ENERGY \\ FEDERAL ASSISTANCE MILESTONE PLAN}

1: PROJECT ID No:

DE - FC07 - 00ID13996 PHASE II

2: PROJECT TITLE:

ROTARY BURNER DEMONSTRATION;

3: PERFORMER: CALCPOS ENGINEERING

PO BOX 906

NORTHFIELD CENTER, OH 44067

4: START DATE : Sept 9, 2001

5: COMPLETION DATE : Sept 29, 2003

\begin{tabular}{|c|c|}
\hline 6:TASK & 7: SUMMARY DESCRIPTION \\
\hline \multicolumn{2}{|l|}{ No: } \\
\hline 6.01 & Site Assessment. Requirements \& Equipment. \\
\hline 6.02 & Site Plan \\
\hline 6.03 & : Site Control \\
\hline 6.04 & Baseline Analysis \\
\hline 6.05 & Design; Mechanical \\
\hline 6.06 & : Design; Control \\
\hline 6.07 & : Materials \\
\hline 6.08 & : Laboratory Test \\
\hline 6.09 & Modifications \\
\hline 6.10 & Commission burner 1 \\
\hline 6.11 & Data acquisition burner 1 \\
\hline 6.12 & Site settings burner 1 \\
\hline 6.13 & Install burners $2 \& 3$ \\
\hline 6.14 & Adjustments burners 2, 3 \\
\hline 6.15 & Site Settings \& Data; burners $1,2,3$ \\
\hline
\end{tabular}

8: COMPLETION DATES

9: \%

[a] Plan

[b] Actual

[c] \%

$02 / 28 / 02$

$02 / 28 / 02$

90

$02 / 28 / 02$

$02 / 28 / 02$

90

$02 / 28 / 02$

02 / 28 / 02

75

$03 / 31 / 02$

02 / 31 / 02

100

$04 / 30$ / 02

02 / 28 / 02

90

$04 / 30 / 02$

$02 / 28 / 02$

90

$01 / 31 / 03$

$01 / 31 / 02$

90

$06 / 30 / 02$

02 / 28 / 02

90

$06 / 30 / 02$

$05 / 30 / 02$

80

$08 / 31 / 02$

$06 / 25 / 02$

95

$08 / 31 / 02$

$00 / 00 / 00$

90

$08 / 31 / 02$

$00 / 00 / 00$

90

$12 / 31 / 02$

$10 / 10 / 00$

75

$12 / 31 / 02$

$00 / 10 / 00$

75

$12 / 31 / 02$

$00 / 00 / 00$

75

PHASE II TASKS PENDING COMPLETE INITIATION FOLLOW BELOW;

$\begin{array}{ll}6.16 & : \text { Install all burners } \\ 6.17 & : \text { Optimize total installation } \\ 6.18 & : \text { Life Testing; All trial burners } \\ 6.19 & : \text { Installation Performance Audit } \\ 6.20 & : \text { Project management \& Reporting }\end{array}$

$\begin{array}{lll}05 / 01 / 03 & 00 / 00 / 00 & 0 \\ 05 / 31 / 03 & 00 / 00 / 00 & 0 \\ 05 / 31 / 03 & 00 / 00 / 00 & 0 \\ 09 / 30 / 03 & 00 / 00 / 00 & 0 \\ 10 / 31 / 03 & 00 / 00 / 00 & 50\end{array}$

NOTES: All tasks incomplete until all burners installed and site acceptance. 